\title{
A spatial analysis of employment multipliers in the U.S.
}

\author{
Margherita Gerolimetto · Stefano \\ Magrini
}

\begin{abstract}
The actual effectiveness of employment promotion policies depends on the ability of the intervention at creating new jobs in the targeted sector, but also, to a large extent, on the impact they have on other parts of the local economy. Estimating the latter effect is therefore quite important for regional economic development policies. Along the lines of Moretti (2010), we present an empirical analysis of local employment multipliers using data on 123 U.S. Metropolitan Statistical Areas over the period 1980-2010. From the methodological point of view, in this work not only endogeneity (via instrumental variables estimates), but also spatial spillovers are taken into account. According to the results, the magnitude of the multiplier could be rather limited. On the other hand, there is clear indication that the impact of these interventions is not fully contained within the local economy and they have a positive effect on closely surrounding ones.
\end{abstract}

This is the accepted version of the article published in the Letters in Spatial and Resource Economics (2015). The final publication is available at Springer via http://dx.doi.org/10.1007/s12076-015-0157-z

Keywords Local Multipliers · Regional Policy · Spatial Models · Instrumental Variable estimation

JEL Classification R11 · O $14 \cdot \mathrm{C} 21 \cdot \mathrm{C} 26$

\author{
M. Gerolimetto \\ Ca' Foscari University Venice, Department of Economics \\ Tel.: +39-041-2347432 \\ Fax: +39-041-2349210 \\ E-mail: margherita.gerolimetto@unive.it \\ S. Magrini \\ Ca' Foscari University Venice, Department of Economics \\ Tel.: +39-041-2349194 \\ Fax: +39-041-2349210 \\ E-mail: s.magrini@unive.it
}




\section{Introduction}

State and local governments employ large amounts of public funds in economic development policies aimed at attracting and fostering new economic activities or at retaining existing ones. The outcomes of these efforts could be new or more stable jobs, higher income and wealth and an improved tax base. Indeed, it appears that job creation has actually represented the primary goal sought after by policy makers (Eberts, 2005) possibly because this may also lead to fiscal benefits in the form of an increase of tax revenue net of public expenditure. In fact, due to multiplier effects, the total increase in local jobs can be greater than the increase in jobs in assisted businesses when these businesses produce tradable goods. For this reason, most of local development interventions are actually targeted to the tradable sector.

In the U.S., a precise account of the total amount of resources involved in these activities is almost an impossible task given the large number of agencies involved and the even larger number of policies being implemented. However, a survey of state-funded programs conducted in 1998 (Poole et al. 1999), calculated that the states allocated approximately $\$ 4.6$ billion in tax incentive programs and $\$ 6.3$ billion in non-tax incentives. This figure excludes tax and other financial incentives, as well as job training and infrastructure incentives provided by local (sub-state) governments; it also excludes local development efforts carried out under the leadership of non-governmental organizations. Eberts (2005) reports an overall estimate of $\$ 30$ billion a year devoted to local development initiatives through direct and indirect funds which implies more than $\$ 2,000$ per targeted job.

To quantify the multiplier effect, Moretti (2010) suggests a method based on a regression framework. Despite its simplicity, this method appears to represent a valid alternative to the traditional one, i.e. local Input-Output analysis, as it allows for offsetting general equilibrium effects. However, one element that is totally overlooked in its practical implementation is the role of spatial spillovers. To address this, here we justify and employ a straight-forward extension of Moretti's specification in which a spatial lag of the explanatory variable is introduced.

The structure of the paper is as follows. In Section 2 the theoretical and empirical frameworks for the estimate of the local nontradable multiplier are presented; Section 3 reports the results of the empirical analysis and Section 4 concludes.

\section{Theoretical and Empirical Framework}

In a recent paper, Moretti (2010) proposes a simple methodology to assess the effectiveness of local development interventions in creating new jobs. The theoretical framework that underlies the empirical analysis builds on the traditional general equilibrium setting by Rosen (1979) and Roback (1982). However, differently from the original Rosen-Roback set-up, in Moretti's framework local 
shocks to local labor markets are not necessarily fully capitalized in the price of land as the local supply of labor is not necessarily infinitely elastic and the local housing supply is not necessarily perfectly inelastic (see also Moretti, 2011). More specifically, a positive shock to the labor demand of an industry within the tradable sector of a given city produces an effect on the employment of the nonstradable sector that depends

- positively, on the magnitude of the resulting increase in the city budget constraint that, in turn, depends directly on consumer preferences for nontradables, on the degree of labor intensity in the nontradable sector and on the average skill of the jobs created in the tradable sector;

- negatively, on the extent of general equilibrium effects on wages and prices which depend, in turn, on housing and local labor supply elasticities: the lower these elasticities, ${ }^{1}$ the larger the crowding out effect to other industries in the tradable sector due to the local increase in housing and labor costs.

Within this framework, therefore, the local nontradable multiplier in a city is the net effect of these two sources of variation.

To get an indication of the size of the multiplier, Moretti (2010) estimates the elasticity of nontradable employment with respect to tradable via the following regression model using data for U.S. cities over the period 1980-2000:

$$
\Delta N_{a t}^{N T}=\alpha+\beta \Delta N_{a t}^{T}+u_{a t}
$$

where $\Delta N_{a t}^{N T}$ and $\Delta N_{a t}^{T}$ are, respectively, the change in the log number of jobs in the nontradable and tradable sector in city $a$ and $u_{a t}$ is a vector of innovations assumed to be independent and identically distributed. Since the sample includes two observations per city, one for each decade in the analyzed period, Moretti also includes a dummy variable for the second decade. To obtain a measure of how many jobs are created in the nontradable sector for each additional job in the tradable sector, the estimated elasticity is then multiplied by the sample ratio between nontradable and tradable jobs:

$$
\text { job per } j o b_{a t}=\hat{\beta} \times \frac{N_{a t}^{N T}}{N_{a t}^{T}}
$$

One particularly appealing feature of this approach is that the exogenous variation is directly attributed to the tradable sector which is the one that attracts most of the local development initiatives (de Blasio and Menon, 2011). More generally, as emphasized by Moretti himself, this approach represents a simple but valid alternative to the traditional methodology, local Input-Output analysis, that tends to overlook the employment effect for nontradables as well as the offsetting general equilibrium effects.

\footnotetext{
1 The elasticity of housing supply depends on geography and land use regulations. The elasticity of local labor depends on the residents' tastes for leisure, the local pool of unemployment and the degree of labor mobility across cities.
} 
There are however two potentially critical issues. The first is represented by a possible inverse causation of the variables in the regression that, in turn, implies endogeneity. Moretti (2010) treats this by adopting the instrumental variables estimator (IV) where the instrument is represented by the potential growth rate that each city would have experienced had its economic subsectors grown at the corresponding national average growth rate. This type of instrument is rather commonly employed since Bartik (1991). Following this strategy, the author finds that an additional job in the tradable sector leads to 2.77 (OLS) or 1.59 (IV) jobs in the nontradable one.

The second critical issue arises from spatial spillovers. In his empirical setup, Moretti analyzes the direct effect of a change of tradable employment in one city on the change in nontradable employment in the same city thus implicitly assuming that each city is completely isolated from the rest of the economy. This assumption, however, appears overly restrictive. Indeed, an examination of the theoretical framework sketched above clearly suggests the existence of spillover effects among spatial units.

To clarify this aspect, assume that a local multiplier actually exists and consider a policy shock that occurs in the labor market of city $a$ and generates new jobs in the local tradable sector. Two types of spatial spillover effects might manifest:

- first, a share of these new jobs is taken up by people that migrate (or commute) from near-by cities, thus producing an impact on the labor markets of origin. From the viewpoint of the latter labor markets, this represents a shock which might have a negative impact on employment in the corresponding nontradable sectors. The size of this impact is likely to fade quite rapidly with the distance between the cities and, given distance, depends on some of the factors mentioned above: the average skill of the jobs created in city $a$ as well as on housing and local labor supply elasticities in all locations;

- second, the increase in the budget constraint of city $a$ leads to an increase in the demand of nontradable goods from its residents. If obstacles to tradability of nontradables goods is less than absolute, then part of this demand increase will benefit producers in near-by cities.

The sign and size of the overall effect felt in a neighboring city $b$ originated from the shock in the tradable sector of city $a$ is very difficult to establish theoretically being the net result of complex forces pushing in opposite directions. Nonetheless, three aspects must be emphasized:

i. whatever its net magnitude, this effect originates from the shock in the tradable sector of city $a$;

ii. given the nature of the interactions across cities, the magnitude of this effect is inversely related to the distance between $a$ and $b$ and possibily vanishes as distance exceeds some threshold measure;

iii. if the employment increase in the tradable sector of $a$ has a direct effect on the level of employment in the nontradable sector of $b$ (either because nontradable workers in $b$ decide to take up newly created jobs in $a$ or 
because part of the increased demand for goods in $a$ is actually met by an increased production of nontradables in $b$ ), the estimated size of the coefficient $\beta$ in (1) might be biased.

In sum, it should be clear that any empirical scrutiny of the size of the local multiplier should resort to a spatial econometric specification. Given the discussion on the specific nature of the spatial spillovers and, in particular, the first of the three aspects just emphasized, we focus on a straight-forward extension of (1) in which a spatial lag of the explanatory variable is introduced. Adopting the notation used in LeSage and Pace (2009), this is known as the SLX model:

$$
\Delta N_{a t}^{N T}=\alpha+\beta \Delta N_{a t}^{T}+\beta^{\prime} \sum_{j=1}^{n} w_{a j} \Delta N_{j t}^{N T}+u_{a t}
$$

where $w_{a j}$ are elements of a spatial-weighting matrix, $W$, providing a description of the interactions between spatial units. The magnitude of a local multiplier effect can then be established from the coefficient estimate of the nonspatial explanatory variable, $\hat{\beta}$, while the relevance of spatial spillover effects is established by the coefficient estimate of the spatially lagged explanatory variable, $\hat{\beta}^{\prime}$. In addition to its simplicity, a further particularly appealing feature of the SLX model in the present context is that, differently from more commonly used spatial specifications such as the SAR (spatial autoregressive) and SAC (spatial autoregressive combined) models, it imposes no prior restrictions in the ratio between the types of effect (Vega and Elhorst, 2015).

To estimate (2), we use a parameterized distance based weights matrix instead of one based on contingency. In particular, we employ a simple inverse distance matrix with a threshold

$$
w_{i j}= \begin{cases}\frac{1}{d_{i j}^{\gamma}} & 0 \leq d_{i j} \leq d \\ 0 & d_{i j}>d\end{cases}
$$

where $d_{i j}$ denotes the distance between observations $i$ and $j, d$ is a distance threshold while $\gamma$, the distance decay parameter, is estimated using a nonlinear estimation technique as suggested by Vega and Elhorst (2015). ${ }^{2}$ By estimating the parameter $\gamma$, rather than imposing it beforehand, the approach suggested by Vega and Elhorst is capable of providing information on the way spatial interactions fade as the distance between units increases.

As for the scaling of the elements of $W$, Vega and Elhorst stress that rownormalizing weights based on inverse distance causes their economic interpretation in terms of distance decay to no longer be valid (Vega and Elhorst, 2015: 356-357; but also Anselin, 1988: 23-24). Therefore, here we opt for a minmaxnormalized matrix (Kelejian and Prucha, 2010: 56) obtained by dividing each

\footnotetext{
2 Details on this technique can be found in Vega and Elhorst (2015). We thank the authors for providing the MATLAB routine.
} 
element $w_{i j}$ by

$$
\tau=\min \left\{\max _{i} \sum_{j=1}^{n} w_{i j}, \max _{j} \sum_{i=1}^{n} w_{i j}\right\} .
$$

\section{Empirical Analysis}

The period covered in the analysis runs from 1980 to 2010. Employment data are estimated using the 5 percent samples from federal census data for 1980 and using the 1 percent samples from the American Community Survey for 2010 obtained from the Integrated Public Use Microdata Series (Ruggles et al. 2010). We pay particular attention to the distinction between tradable and non tradable sectors: rather that adopting the traditional classification that identifies tradable industries with manufacturing, we use the two-digit NAICS code classification provided by Hufbauer and Vieiro (2013) following the approach developed by Jensen and Kletzer (2005). According to this approach, when production is concentrated at a distance from consumption within the U.S., as inferable from a locational Gini coefficient exceeding 0.1, the activity is classified as tradable. ${ }^{3}$

To isolate exogenous shifts in the demand for labor in the tradable sector, we use a variation of the instrument suggested by Moretti (2010), i.e. a weighted average of statewide employment growth by 84 industries (classified according to the 1990 Census Bureau industrial classification scheme) within the tradable sector, with weights reflecting their location-specific employment share in 1980. While Moretti (2010) employs nationwide counterfactual tradable employment growth, we opt for statewise growth because the type of policy interventions considered here are at times implemented at the State level; in addition, the timing of business cycles differs substantially across States (Magrini et al. 2015).

As for the choice of the territorial unit of the analysis we opt for the metropolitan area. In a recent paper, Arbia and Petrarca (2011) analyze the effects of the Modifiable Areal Unit Problem (MAUP) ${ }^{4}$ (Gehlke and Biehl, 1934; Openshaw and Taylor, 1979; Openshaw, 1984; Arbia, 1989) on linear spatial econometric models. More specifically, they confirm the loss in efficiency of the parameters' estimates due to aggregation (e.g. different partitions of a territory at a given scale). Among the practical ways to address the MAUP, Arbia (2001) suggests the use of units characterized by "significant boundaries" from

\footnotetext{
3 Since data in the Integrated Public Use Microdata Series are originally classified according to the 1990 Census Bureau industrial classification scheme, we mapped them into the two-digit NAICS code classification using industry code crosswalks provided by the US Census Bureau. As in Moretti (2010) we exclude agriculture, mining, government and the military.

4 The MAUP relates to the fact that imposing artificial boundaries on a continuous geographical phenomenon generates artificial spatial patterns and the spatial patterns generated at different spatial scales or with different aggregation criteria differ from each other.
} 
Table 1 Regression Results and Local Multipliers

\begin{tabular}{|c|c|c|c|c|}
\hline & & $\begin{array}{l}\text { non-spatial } \\
\text { IV }\end{array}$ & $\begin{array}{c}\text { SLX } \\
\text { fixed-effects IV }\end{array}$ & $\begin{array}{l}\text { SLX } \\
\text { IV }\end{array}$ \\
\hline$\beta$ & & 0.618 & 0.573 & 0.629 \\
\hline$p$-value & & 0.000 & 0.000 & 0.000 \\
\hline$\beta^{\prime}$ & & & 0.221 & 0.136 \\
\hline$p$-value & & & 0.059 & 0.018 \\
\hline$\gamma$ & & & 1.185 & 0.979 \\
\hline$p$-value & & & 0.000 & 0.000 \\
\hline job-per-job & & 0.53 & 0.49 & 0.54 \\
\hline Endogeneity (Durbin) test & & 16.126 & 16.080 & 14.486 \\
\hline$p$-value & & 0.000 & 0.000 & 0.000 \\
\hline Endogeneity (Wu-Hausman) test & & 16.635 & & 14.832 \\
\hline$p$-value & & 0.000 & & 0.000 \\
\hline Underidentification (Anderson) test & & 94.358 & 39.313 & 97.505 \\
\hline$p$-value & & 0.000 & 0.000 & 0.000 \\
\hline Weak identification (Cragg-Donald) test & & 125.403 & 22.92 & 65.185 \\
\hline \multirow[t]{3}{*}{ 2SLS size of nominal $5 \%$ Wald test } & $10 \%$ & 16.38 & 19.93 & 19.93 \\
\hline & $15 \%$ & 8.96 & 11.59 & 11.59 \\
\hline & $20 \%$ & 6.66 & 8.75 & 8.75 \\
\hline Overidentification (Sargan) test & & & 0.637 & 0.044 \\
\hline$p$-value & & & 0.425 & 0.833 \\
\hline Joint $\mathrm{F}$ test for fixed-effects & & & 0.660 & \\
\hline$p$-value & & & 0.995 & \\
\hline
\end{tabular}

Notes: All models include time-specific fixed effects. Estimates are produced using MATLAB and STATA. The dataset, the MATLAB routines for the estimation of $\gamma$ and the STATA code for estimates and tests will be made available at the web site of the second author.

an economic standpoint. Hence, we choose the metropolitan area given that this is considered the most appropriate in approximating the boundaries of a local labor market, i.e. the basic spatial unit where the policy interventions should deploy their effects. Due to limitations in the availability of data on employment at the level of disaggregation required for the construction of the instrument, we are however forced to restrict the analysis to a subset of 123 Metropolitan Statistical Areas. A map with the location of the selected MSAs in displayed in Figure 1.

We produce two sets of estimates which are reported in Table 1. First, we conduct a traditional, non-spatial IV analysis using statewide counterfactual growth of tradable employment as an instrument. The estimated elasticity of nontradable employment with respect to tradable employment is equal 0.618 and indicates that a ten percent increase in the number of tradable jobs in a metropolitan area is associated with a 6.2 percent increase the local nontradable sector. Given that, over the analyzed period, there are approximately 0.86 nontradable jobs for each tradable job in our dataset, the IV estimate implies that, for each additional job in the tradable sectors in a given metropolitan area, 0.53 jobs are created in the corresponding nontradable sector; this is indeed a much lower value than the corresponding one (1.59) reported by Moretti. 
Then, we proceed with the SLX estimates. The first specification includes MSA-specific fixed effects (in addition to the usual time-specific fixed effects) to control for the possible role of location specific characteristics: geography and land use regulations might affect the elasticity of housing supply while and residents' tastes for leisure and location might affect the elasticity of local labor supply. As instruments, we use statewide counterfactual growth of tradable employment and its spatial lag. The estimated elasticity of nontradable employment with respect to tradable employment is now equal 0.573 , implying that, for each additional job in the tradable sectors, 0.49 jobs are created in the corresponding nontradable sector. In addition, the estimate of the distance decay parameter is 1.185 and highly significant while and the spillover effect is positive with an elasticity of 0.221 and marginally significant $(p$-level $=0.06)$. The interpretation of this latter estimate is that a positive increase in tradable sector employment in a metropolitan area leads to increased nontradable employment in neighboring areas. However, a joint F-test clearly cannot reject the null hypothesis that all of the location fixed effect intercepts are zero so our final specification excludes them. In this case, the elasticity of nontradable employment with respect to tradable is 0.629 suggesting that 0.54 nontradable jobs are created for each additional job in the tradable sector. The estimated distance decay parameter is very close to 1 (0.979) and highly significant, and the spillover effect is positive (0.136) and significant. ${ }^{5}$ Reported diagnostics confirm that the growth rate of tradable employment is indeed endogenous and reassure about the validity and strength of the instruments.

\section{Conclusions}

The purpose of this work is to investigate the effect of employment promotion policies in the United States. In general, this effect depends on the ability of the intervention at creating new jobs in the targeted area, but also, to a large extent, on the impact they have on other parts of the local economy. Estimating the latter component of the local multiplier, is therefore, important for regional economic development policies.

To establish the size of the local nontradable multiplier we have employed data on employment by narrowly defined industries for 123 U.S. metropolitan areas between 1980 and 2010, paying particular attention to the distinction between tradable and non tradable sectors.

From the methodological point of view, in this work not only endogeneity (via instrumental variables estimates), but also spatial spillovers are taken into account. In particular, on the basis a simple theoretical framework we have concentrated on a SLX specification in which, following Vega and Elhorst (2015), the distance decay parameter of a parametrized distance based $W$ matrix is estimated using a nonlinear estimation technique rather than

5 We have also estimated the same model using a $W$ matrix with no threshold. Results are analogous but the spillover effect becomes slightly weaker (0.0930 with a $p$-level of 0.069$)$. 
imposed beforehand. According to our estimates, the magnitude of the multiplier is rather limited and certainly much smaller than the value reported by Moretti (2010). In addition, the estimated distance decay parameter is very close to 1 (0.979) and highly significant while spatial spillovers appear to affect positively and significantly employment growth in nontradable sectors.

Acknowledgements We gratefully acknowledge two anonymous referees for their insightful comments and constructive suggestions that have helped to significantly improve this work. Needless to say, all errors and remaining infelicities of style are our own responsibility.

Fig. 1 Map of MSAs included in the analysis

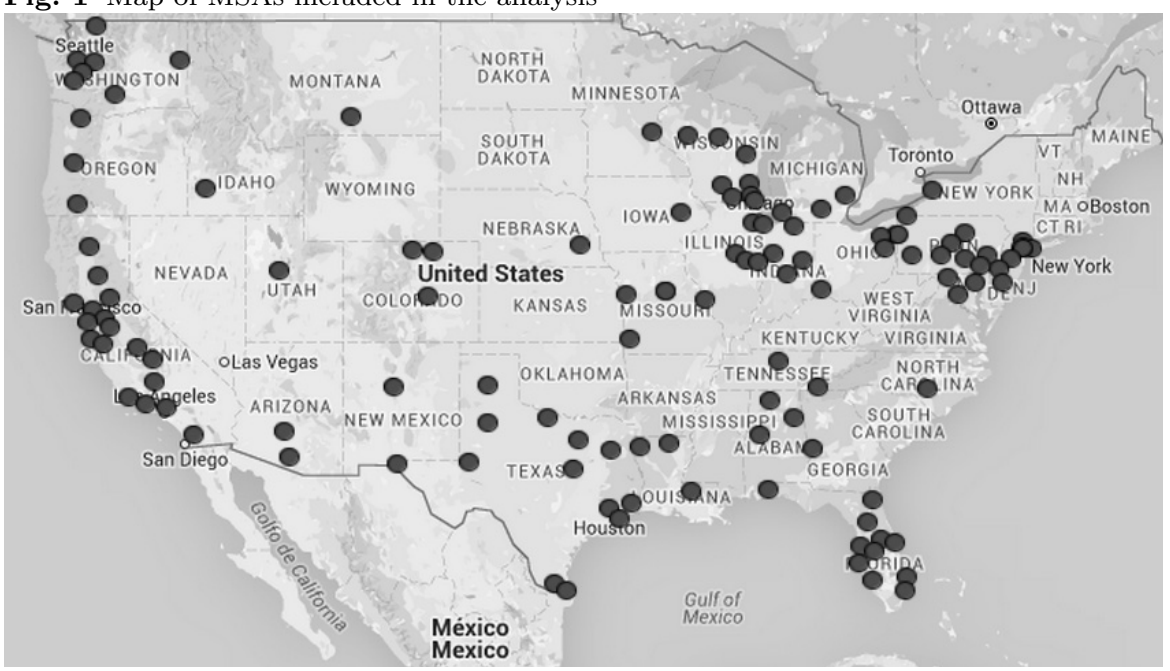

\section{References}

1. Anselin, L.: Spatial Econometrics: Methods and Models, Kluwer, Dordrecht (1988)

2. Arbia, G.: Spatial Data Configuration in Statistical Analysis of Regional Economic and Related Problems, Kluwer, London (1989)

3. Arbia, G.: Modelling the Geography of Economic Activities in a Continuous Space, Papers in Regional Sciences, 80, 411-424 (2001)

4. Arbia, G., Petrarca, F.: Effects of MAUP on Spatial Econometric Models, Letters in Spatial and Resource Science, 4, 173-185 (2011)

5. Bartik, T.J.: Who Benefits from State and Local Economic Development Policies?, W.E. Upjohn Institute for Employment Research, Kalamazoo, MI (1991)

6. de Blasio, G., Menon C.: Local Effects of Manufacturing Employment Growth in Italy, Giornale degli Economisti e Annali di Economia, 70, 101-112 (2011) 
7. Eberts, R.W.: Overview of State and Local Economic Development Policies and Practice in the United States, In: Giguère S.Y. Higuchi and the Japan Institute for Labour Policy and Training (eds.), Local Governance for Promoting Employment: Comparing the Performance of Japan and Seven Countries, 87-102. The Japan Institute for Labour Policy and Training, Tokyo (2005)

8. Gehlke, C.E., Biehl, K.: Certain Effects of Grouping Upon the Size of the Correlation Coefficient in Census Tract Material, Journal of the American Statistical Association, 29, 169-170 (1934)

9. Hufbauer G.C., Vieiro, M.: Corporate Taxation and US MNCs: Ensuring a Competitive Economy, Policy Brief 13-9, Peterson Institute for International Economics, Washington, DC (2013)

10. Jensen, J.B., Kletzer, L.: Tradable Services: Understanding the Scope and Impact of Services Outsourcing, In: Working paper No. 05-9, Institute of International Economics, Washington, DC (2005)

11. Kelejian, H.H., Prucha I.R.: Specification and Estimation of Spatial Autoregressive Models with Autoregressive and Heteroskedastic Disturbances, Journal of Econometrics, 157, 53-67 (2010)

12. LeSage, J.P., Pace, R.K.: Introduction to Spatial Econometrics. Taylor and Francis, Boca Raton, FL (2009)

13. Magrini, S., Gerolimetto, M, Duran, H.E.: Regional Convergence and Aggregate Business Cycle in the United States, Regional Studies, 49, 251-272 (2015)

14. Moretti E.: Local Multipliers, American Economic Review: Papers and Proceedings, 100, 373-377 (2010)

15. Moretti, E.: Local Labor Markets, In: Ashenfelter O., Card, D. (eds.), Handbook of Labor Economics, 4B, 1237-1313. North-Holland Elsevier, Amsterdam (2011)

16. Openshaw, S.: The Modifiable Areal Unit Problem, GeoBooks, Norwich (1984)

17. Openshaw, S., Taylor P.J.: A Million or So of Correlation Coefficients: Three Experiments on the Modifiable Areal Unit Problem, In: Wrigley, N. (ed.), Statistical Applications in the Spatial Sciences, Pion, London (1979)

18. Poole, K.E., Erickcek, G.A., Iannone, D.T., McCrea, N., Salem, P.: Evaluating Business Development Incentives, National Association of State Development Agencies, Washington, DC (1999)

19. Roback, J.: Wages, Rents and the Quality of Life, Journal of Political Economy, 90, $1257-1278$ (1982)

20. Rosen, S.: Wage-based Indexes of Urban Quality of Life, In: Miezkowski, P., Straszheim, M.R. (eds.), Current Issues in Urban Economics, 74-104. Johns Hopkins University Press, Baltimore (1979)

21. Ruggles, S., Alexander, J.T., Genadek, K., Goeken, R., Schroeder, M.B., Sobek, M.: Integrated Public Use Microdata Series: Version 5.0 [Machine-readable database]. Minnesota Population Center, Minneapolis (2010)

22. Vega, S.H., Elhorst, P.J.: The SLX Model, Journal of Regional Science, 55, 339-363 (2015) 